\title{
História, ciência ou romance? O tema das identidades no futebol brasileiro
}

Daniel Ferreira

\section{RESUMO}

Já há algum tempo, uma percepção de crise vem se manifestando no campo das ciências humanas e, por consequência, no campo historiográfico acerca do status de ciência para História de uma forma geral. Trata-se de uma questão de cunho epistemológico e que, assim sendo, repercute e desafia historiadores como um todo, independente das especificidades do seu objeto. O objetivo central deste artigo é problematizar o campo de estudos históricos envolvendo identidade e futebol que se desenvolve no Brasil, a luz daquele diagnóstico de crise. Para tal, parte-se de uma breve apresentação da referida crise, destacando a proposta historiográfica de Jörn Rüsen como forma de superá-la. $\mathrm{Na}$ sequência, a partir de uma dada escolha bibliográfica, apresenta-se um panorama geral sobre estudos, no Brasil, envolvendo o tema das identidades no futebol. Finalmente, conclui-se o artigo com alguns apontamentos e a possibilidade do uso da teoria elisiana na escrita da história do esporte.

Palavras-chave: Futebol. Historiografia. Identidades

1 Doutorando em História na Universidade Federal do Paraná (UFPR). Curitiba/Paraná, Brasil. E-mail: ferreir_10@ yahoo.com.br 
History, science or romance? The theme of identities in brazilian football

\begin{abstract}
There is some time, a perception of crisis has been manifesting in the field of human sciences and, consequently, in the historiographic field about the status of science for History in general. It is a question of epistemological nature and, as such, it reverberates and challenges historians as a whole, independent of the specificities of its object. The central aim of this article is to problematize the field of historical studies involving identity and football that develops in Brazil, in light of that crisis diagnosis. For this, a brief presentation of that crisis is realized, highlighting the historiographic proposal of Jörn Rüsen as a way of overcoming it. Following, from a given bibliographic choice, an overview is presented about studies in Brazil involving the theme of football's identities. Finally, the article concludes with some notes and the possibility of the use of the elisiana theory in the sport's historiography.
\end{abstract}

Keywords: Football. Historiography. Identities

Historia, ciencia o romance? El tema de las identidades en el fútbol brasileño

\title{
RESUMEN
}

Hace algún tiempo, una percepción de crisis viene manifestándose en el campo de las ciencias humanas y, por consiguiente, en el campo historiográfico acerca del status de ciencia a la Historia de una forma general. Se trata de una cuestión de cuño epistemológico y que, así, repercute y desafía a historiadores como un todo, independiente de las especificidades de su objeto. En este artículo, el objetivo central es problematizar el campo de los estudios históricos sobre identidad y fútbol en Brasil a partir del diagnóstico de crisis. Para eso, presenta lo que es esa crisis, destacando la propuesta de Jörn Rüsen como forma de superarla. Después, desde de una elección bibliográfica, se presenta una descripción general de los estudios en Brasil sobre el tema de las identidades en el fútbol. Por fin, se concluye con apuntes y la posibilidad del uso de la teoría elisiana en la historiografía del deporte.

Palabras-clave: Fútbol. Historiografía. Identidad

\section{INTRODUÇÃO}

O campo acadêmico de estudos do futebol, no Brasil, se desenvolveu consagrando a categoria da brasilidade como um paradigma recorrente e de certa forma predominante em pesquisas que tratam da identidade no esporte. Este artigo tem o objetivo de debater a 
História como narrativa dentro do campo esportivo, problematizando, para tal, justamente a frequência daquela abordagem de "identidade nacional" nos estudos do esporte. Esta escolha se justifica porque um debate significativo e mais amplo, já há algum tempo, vem se desenvolvendo no campo das ciências humanas em geral, e mais especificamente no campo historiográfico em termos epistemológicos. Este debate vem problematizando o próprio status e papel da história enquanto ciência.

Para desenvolver a referida análise da narrativa da "identidade nacional" inserida no campo esportivo, foram selecionadas algumas obras e autores considerados clássicos, de frequente referência, ou que se acredita que pudessem dar os contornos mais claros sobre o panorama exposto, sem obviamente a pretensão de encerrar ou mesmo de considerar essa seleção como a única possível. Uma breve referência a um levantamento recente da produção acadêmica nos encontros da Associação Nacional de Professores Universitários de História (ANPUH) no âmbito nacional, e das regionais São Paulo e Paraná, também é contemplada.

Dessa forma o presente artigo está dividido da seguinte forma: primeiramente apresenta-se um panorama geral do que seria a chamada "crise na História", e como ela tem se caracterizado por debates acalorados, de diferentes concepções historiográficas e pelo questionamento da História como ciência. Destacamos como esse debate pode ser contemplado em trabalhos cuja temática é identidade no futebol, em especial sobre leituras do futebol a partir de uma ideia de regionalidade, ou de leituras do futebol a partir da categoria brasilidade e da "identidade nacional", estas últimas muito recorrentes. Finalmente, encerramos fazendo alguns apontamentos, e apresentando brevemente a teoria elisiana como um caminho possível, entre outros, para superar a crise na escrita da história do desporto.

A crise na escrita da História

\begin{abstract}
"Tempo de incerteza", "crise epistemológica", "reviravolta crítica": esses são os diagnósticos, geralmente inquietos, feitos nos últimos anos sobre a história (...) Eles designam, creio, esta mutação maior que é o apagamento dos modelos de compreensão, dos princípios de intelegibilidade que tinham sido aceitos de comum acordo pelos historiadores (ou, pelo menos, pela maioria deles) a partir dos anos 60 (CHARTIER, 2002, p.81).
\end{abstract}

A afirmação acima é do historiador Roger Chartier, considerando a existência de uma incômoda questão posta, na ordem dos dias atuais, ao ofício dos historiadores: a crise dos paradigmas estruturalistas e "galileanos"2 na História estaria motivando um conflito entre se fazer a História como narrativa, ou pela continuidade da História através do modelo que se consagrou como "ciência". Em outras palavras, um conflito que ameaça o status

2 Cf. GINZBURG, Carlo. Sinais: raízes de um paradigma indiciário. In: Mitos, emblemas, sinais: Morfologia e História. São Paulo: Companhia das Letras, 1990. Trata-se de um termo utilizado por Ginzburg, para referir-se ao postulado de quantificação na ciência da História, baseado em pressupostos advindos da constituição das ciências naturais. 
da História como "ciência". Chartier não foi o único a ter se debruçado sobre a questão. Hayden White, Carlo Ginzburg e Jörn Rüsen, apenas para citar alguns nomes muito bem reconhecidos entre os historiadores, são outros intelectuais que já trataram detidamente sobre o problema. E tal como o intelectual francês, eles ressaltaram a necessidade da discussão da História enquanto prática científica. Abordarei, brevemente, essas perspectivas para ilustrar o problema.

Para White, um dos representantes da chamada linguistic turn, a História é antes de tudo um exercício narrativo, ou seja, toda explanação histórica seria retórica e poética por natureza (WHITE, 2002). Esta afirmação se sustenta a partir de uma análise sua da História, sobre a perspectiva da escrita e, por conseguinte, do estudo da linguagem (ou das linguagens) da historiografia, tendo como fonte autores clássicos tais como Marx, Michelet, Ranke, entre outros. Segundo ele, o historiador precisaria utilizar estratégias retóricas, metafóricas e ideológicas para recuperar o passado, somado a própria posição social do historiador que influiria na sua escrita, o que o leva a questionar a objetividade e a possibilidade da verdade na pesquisa histórica. Em síntese, White aproxima a historiografia das narrativas ficcionais em termos epistemológicos, problematizando dessa maneira seu status consagrado de ciência e, por consequência, de verdade e poder.

Os trabalhos de White, ou melhor, a linha adotada pelo americano sofreu muitas críticas no campo científico. Pode-se afirmar que um dos expoentes nesse debate crítico à linha de White é o historiador italiano Carlo Ginzburg. Para este, White seguiria uma linha cuja matriz seria nietzschiana, esta a qual haveria inspirado outros intelectuais chamados desconstrucionistas, tais como Roland Barthes, Paul De Man, Jacques Derrida, Marcel Proust, Michel Foucault (entre outros) e que, enfim, entenderiam a História apenas como um exercício de retórica. Ginzburg (2002) defenderá que a ideia consagrada por Nietzsche de que retórica e prova (o equivalente a "verdade" para o historiador) eram necessariamente opostos, não se verificaria: pela tradição aristotélica a retórica deveria vir sempre acompanhada pela prova, portanto qualificar a História como exercício retórico, a partir da perspectiva aristotélica, não implicaria retirar-lhe seu status de ciência e de verdade:

A construção não é incompatível com a prova. A projeção do desejo, sem o qual não há pesquisa, não é incompatível com os desmentidos infligidos pelos princípios de realidade. O conhecimento (mesmo o conhecimento histórico) é possível (GINZBURG, 2002, p.45).

Mais do que isso, entender a História enquanto ciência implicaria num porto seguro, um ponto comum, para que de fato houvesse a possibilidade de uma universalidade de "histórias plurais":

Como se verá a discussão sobre história, retórica e prova levanta uma questão que interessa a todos: a convivência e o choque de culturas. Aceitar a existência de valores e costumes diversos aos nossos parece a muitos obrigatórios; aceitá-los sempre de qualquer maneira parece a alguns intolerável (GINZBURG, 2002, p.14). 
Jörn Rüsen, por sua vez, defenderá que o exercício historiográfico - a meta-história, ou o que ele chama de "processo de geração de sentidos" - seria um processo muito mais amplo e complexo do que supunham White e aqueles que seguiam a sua linha. A narrativa do historiador seria apenas um dos momentos em que este processo se manifestaria, sendo composta, ainda, por outras etapas.

Nesta linha, Rüsen defende que todo ser humano - desde as sociedades mais primitivas (em termos de domínio da natureza) e antepassadas, em relação às nossas - é impelido, pela própria sobrevivência, para criar um sentido no seu presente sobre as experiências vividas ou sobre o seu passado (individual ou em grupo) de forma que articule estas mudanças temporais com suas perspectivas de futuro. O historiador define este processo com o termo cultura. Seria próprio da consciência humana, portanto, desenvolver formas de interpretar e compreender-se historicamente, orientando-se para ações. Para Rüsen, o historiador também desenvolveria este processo, embora de forma "profissional", de forma muito mais sofisticada e a partir de um lugar de poder: "Somos o palácio da criação do sentido histórico" (RUSEN, 2013), afirma.

Rüsen defende ainda que a História, nos dias atuais, desenvolveu novas perspectivas enquanto ciência, perspectivas que estão inter-relacionadas aos questionamentos de ideais da modernidade entre eles a própria ciência/razão como pretensos elementos de progresso e emancipacionistas da humanidade. Ou seja, na História, atualmente, questiona-se uma tradição científica que consagraria elementos de modernidade em sua epistemologia, elementos que dariam um sentido de evocar a modernidade como mensagem dissimulada no processo de construção de fatos passados.

Dessa forma, Rüsen constata existir uma verdadeira crise de orientação na historiografia, acima já referida: História enquanto ciência versus História como ficção. Os "historiadores pós-modernos" negariam a possibilidade de uma História universal - porque esta enclausuraria o passado com seus conceitos pré-estabelecidos - reivindicando "histórias" e múltiplas interpretações. Apesar disso, Rüsen defende que a História não pode abandonar seu status de ciência e, portanto, de orientação e de sentido, pois isto apenas imporia outra lógica, outro sentido: o do caos e da não sustentabilidade, enfim um sentido contrário a não existência humana pensada de uma forma global, integrada, enfim histórica. Por outro lado, o historiador alemão incorpora muito das críticas dos "historiadores pós-modernos" defendendo que a multiplicidade de Histórias é necessária, porém a partir de uma representação mental de uma unidade de experiência histórica. O desafio seria integrar alguns elementos do que chama História moderna com elementos da História pós-moderna, sintetizando a proposta da seguinte forma:

Como podemos produzir, contudo, uma concepção da universalidade da evolução histórica e aceitar simultaneamente que só existe uma multiplicidade de histórias diferentes ou um multiperspectivismo no pensamento histórico? Penso no princípio normativo do reconhecimento recíproco de diferenças na vida humana. Esse princípio pode ser elaborado em uma estrutura cognitiva, e essa estrutura pode produzir um novo acesso à experiência histórica, que liga a unidade da humanidade e da evolução no tempo com a diferença das culturas, por um lado, e com sua multiplicidade, por outro lado. É preciso fundir micro e macro história (RÜSEN, 2013, p. 11). 
Essas questões envolvendo o ofício do historiador, ciência, e o "processo de geração de sentido", podem ser contempladas a partir de casos concretos, ou de uma determinada bibliografia a respeito de uma dada temática. Conforme destacamos inicialmente, nosso propósito neste trabalho é problematizar a temática das identidades na bibliografia sobre futebol que se consagra no campo acadêmico brasileiro, o que faremos a seguir.

Antes, é importante dizer que no Brasil desenvolveram-se inúmeros estudos sobre identidades no futebol. Há certa recorrência, neles, da leitura da realidade social a partir da categoria regionalismo, e isso aconteceu tanto dentro como fora da academia. Neste campo, porém, consagrou-se de forma mais recorrente a leitura do futebol a partir de outro sentido histórico: a brasilidade. Isto evidencia, portanto, a constatação de Rüsen antes apresentada sobre o sentido histórico em narrativas de História e explicita, por consequência, um desafio colocado aos historiadores do esporte no Brasil.

\title{
Subjetividades no futebol brasileiro: o regionalismo como principio gerador de sentido
}

\begin{abstract}
...eu trabalhei em São Paulo (...) Olha o cidadão que está fazendo rádio em São Paulo ele comenta o Corinthians o tempo todo, o Palmeiras...eles não querem saber se o Coritiba está bem ou está mal, quando tá maravilhoso eles dão uma linha. Ninguém fala da gente! É difícil, se a gente não berrar aqui (...) O personagem do Paraná tem uma dificuldade de parabenizar as pessoas (...) então nós temos que nos defender, criar um biombo pra isso (HIDALGO, 2011).
\end{abstract}

O trecho acima é de um depoimento de um ex-jogador de futebol da década de 1970 do Coritiba Foot Ball Club, clube de futebol profissional da região sul do Brasil. Capitão Hidalgo, como ficou conhecido, tornou-se posteriormente cronista esportivo na região deste clube. Procuro destacar, rapidamente, alguns elementos presentes no depoimento de Hidalgo: primeiro, um sentimento que poderíamos considerar militante e ao mesmo tempo afetivo com o que considera o "Paraná"; segundo, a própria construção de um lugar de poder, um lugar de fala, no caso o "Paraná"; e finalmente terceiro, uma consideração, por Hidalgo, de que houve um descaso com este "Paraná" aludido.

Esses elementos, presentes no discurso de Hidalgo, são recorrentes em outras falas de indivíduos ligados ao campo esportivo do futebol paranaense, conforme pesquisa realizada pelo autor ${ }^{3}$. Ou seja, o passado é reconstruído a partir de uma ideia de sentido que contempla a centralidade da região como ponto de vista.

Esse tipo de narrativa tampouco é percebida apenas para o caso do futebol do Paraná: discursos parecidos, em que há uma referência afetiva entre clubes e região, são recorrentes também em falas e no próprio discurso da imprensa esportiva de outras regiões do país ao longo da história. Ou seja, há historicamente o que poderíamos chamar de

3 Cf. RIBEIRO, Luiz Carlos \& FERREIRA, Daniel. Um registro regional do nacional: memórias do jornalismo paranaense. Memórias do jornalismo paranaense. XI encontro nacional de história oral, Rio de janeiro: 2012. 
um regionalismo no futebol, estabelecido nessa configuração social. Tal fenômeno pode ser considerado uma expressão histórica nativa da crônica esportiva e mesmo da própria comunidade futebolística brasileira em geral, sendo ainda recorrentemente utilizada: na crônica esportiva é recorrente, ainda, nos dias atuais ouvir-se a apresentação de um clube a partir da sua unidade federativa, por exemplo, ao falar de um clube do estado do Paraná usa-se o termo "o paranaense", estendendo-se a mesma situação para falar de um clube "carioca", de um "paulista", "mineiro", "gaúcho", "baiano" e tantos outros exemplos mais, possíveis no futebol brasileiro, em que ocorre a associação simbólica entre clubes e unidades federativas, seja como referência por terceiros ou como a própria "narrativa de si".

O próprio campo acadêmico comprova também que o regionalismo é uma categoria que merece atenção, como identidade expressa historicamente. Giullianotti (1999), por exemplo, afirma que a associação entre identidades e região aconteceria no futebol porque o esporte oferece um terreno fértil para ela acontecer, já que se fundaria (por si só) numa lógica de oposição binária de indivíduos e grupos (díade) integrando e ao mesmo tempo segregando indivíduos em diferentes níveis. O nível regional seria apenas um desses níveis de oposição, entre outros possíveis, como a própria oposição simples entre jogadores, depois entre times, entre clubes e suas tradições podendo atingir, enfim, embates envolvendo clubes de regiões diferentes e mesmo entre nações. Essas oposições seriam ocasiões ricas para construções de alteridades e narrativas em torno de valores, símbolos, história, enfim: identidades de diversas naturezas (racial, cultural, econômica, etc.), integrando (semântica) e opondo (sintaxe) grupos de indivíduos e expressando de alguma forma os dilemas da própria sociedade em torno daqueles elementos. Seria, portanto, nessas bases que a expressão de identidades regionais atuaria.

Entre autores brasileiros, o antropólogo Arlei Damo (1998) segue em linha parecida a Giullianotti, defendendo que o futebol proporciona um espaço para que construções de cunho regional venham à tona já que o esporte, em alguns torneios como o Campeonato Brasileiro de Futebol ou a Copa do Brasil, se baseia no enfrentamento de clubes de diferentes regiões do país, imersos em realidades sociais, econômicas, raciais e culturais muito distintas. Um de seus trabalhos, que mais se aprofunda nessa direção, é a sua dissertação de mestrado, ocasião em que analisa a relação entre o que chama de gauchismo e a identidade clubística gremista. Sua análise é que no Rio Grande do Sul, historicamente, consagrou-se uma dada construção, uma narrativa sobre o gaúcho, que por ocasião de algumas campanhas do time gremista, em torneios nacionais, viriam à tona nos discursos nas mídias, seja de dentro ou de fora do Rio Grande do Sul (DAMO, 1998).

Artur Vasconcelos (2011), na dissertação "Identidade futebolística: os torcedores "mistos" no Nordeste", abordou também a questão das identidades regionais no futebol, trabalhando com uma questão peculiar: o chamado "torcedor misto" nordestino (descrito como o indivíduo que torce por um clube local, e outro clube com destaque nacional geralmente do Rio de Janeiro ou São Paulo). O misto seria uma expressão de estigma utilizada por parte de alguns grupos torcedores no nordeste que atribuiriam a si um papel de não mistos, de puros, e que defenderiam a ideia de apenas um clube para torcer pelo nordestino: o da sua região de origem. Por estes grupos, a região nordestina seria construída e militada 
como um local homogêneo, rural, tradicional e injustiçado em contraposição ao Sudeste, urbano e imperialista onde haveria times favorecidos pela estrutura política e econômica do país. O misto seria assim apresentado como oposto daquele que se enxergaria como não misto: um sujeito alienado, aculturado, "impuro" e também "traidor da sua região".

Enfim, o que se quer destacar é que, seguindo-se na perspectiva de Jörn Rüsen, pode-se afirmar que o regionalismo, acima aludido, seja ele expresso na sociedade por um ator da configuração esportiva (como o caso do cronista apresentado), seja ele expresso na configuração acadêmica, seriam exemplos emblemáticos do chamado "processo de geração de sentido" envolvendo memórias e identidades. Processo este em que se articula passado, presente e futuro, centrado em uma leitura da realidade social a partir de um ponto de vista regional (neste caso), conforme já destacado.

Essa constatação merece destaque, sobretudo, porque vão ser encontradas com mais recorrência na bibliografia sobre futebol no país, narrativas que vão destacar justamente um ponto de vista nacional. Ou seja, se produziram mais narrativas centradas em uma orientação de sentido de nacionalidade ou brasilidade para os fenômenos ocorridos na História do futebol brasileiro. Abordarei esse modelo na sequência.

\title{
Subjetividades no futebol brasileiro: a brasilidade como missão de modernidade
}

\begin{abstract}
...o nosso estilo de jogar foot-ball me parece contrastar com o dos europeus por um conjunto de qualidades de surpresa, de manha, de astúcia, de ligeireza e ao mesmo tempo de espontaneidade individual. Os nossos passes, os nossos pitus, os nossos despistamentos, o alguma coisa de dança e de capoeiragem marcam o estilo brasileiro de jogar o foot-ball, que arredonda e adoça o jogo inventado pelos ingleses e por eles e por muitos outros europeus jogado tão angulosamente (FREYRE, 1967, p. 432).
\end{abstract}

A afirmação acima é de Gilberto Freyre acerca da participação brasileira na copa da França, em 1938. Freyre pode ser visto como um dos pioneiros na abordagem do futebol a partir da perspectiva da identidade nacional, num contexto histórico em que se destacava uma discussão mais ampla sobre "o que seria o Brasil", sobre "qual seria a nossa identidade" e "nossos sentimentos". Discussão a qual participaram (e ainda participam) intelectuais como Sérgio Buarque de Holanda, Caio Prado Júnior, Octavio lanni, Boris Fausto, Francisco Weffort, Florestan Fernandes, Darcy Ribeiro, com visões diferentes. Ribeiro (2012), afirma que essa discussão acontece (e seria uma discussão que extravasa os domínios acadêmicos) entre os intelectuais no Brasil porque estes pensadores teriam incorporado, naquele momento, uma tarefa de "inventar" o Brasil (um país recém-república, em meio a uma população tão heterogênea) num momento de reconfiguração mundial, e pensavam numa modernidade para o país.

O fato é que o argumento de Freyre acaba se consolidando na historiografia do futebol brasileiro, sobretudo a partir de Mário Filho e sua obra O negro no futebol brasileiro 
$(1947)^{4}$, que incorpora o referido argumento. E podemos fazer, inclusive, uma breve alusão a algumas referências respeitadas de estudos que seguiram a perspectiva de Filho: Roberto Da Matta, os estudos de Joel Rufino dos Santos, Simoni Guedes, Waldenir Caldas, José Sérgio Leite Lopes, Cesar Gordon Júnior (entre outros). E ainda, as recentes obras $A$ dança dos deuses (2007) de Hilário Franco Júnior e Veneno remédio (2008), de José Miguel Wisnik.

No caso de Roberto Da Matta, é importante destacar que ele foi um dos pioneiros no estudo do futebol como objeto nas ciências sociais. Suas análises trataram da inserção do esporte no país (século XX), relacionando-o com identidade nacional. Partindo de uma abordagem antropológica, suas análises situam o futebol como um espaço onde o brasileiro comum efetivamente pôde experimentar o sentimento de democracia e da liberdade (ao contrário de outros espaços), já que o jogo promoveria, por exemplo, funcionamento efetivo (e "às claras") de valores burgueses: mérito, isonomia, justiça, possibilidade de vitórias coletivas, engajamentos contraditórios e respeito à parte vencida/derrotada (DA MATTA, 1994). Também, para Da Matta, a análise do futebol ofereceria a percepção de sentimentos disseminados na sociedade brasileira de religiosidade (como, por exemplo, a ideia da predestinação) e também aqueles ligados a uma cordialidade intrínseca ao brasileiro. E ainda, outros sentimentos ligados ao seu descrédito sobre o cumprimento das regras e do compromisso no espaço público (a confusão recorrente entre o público e o privado). Assim, Da Matta inovou abordando o estudo do futebol no meio acadêmico, entretanto o argumento do futebol como "explicação do Brasil" reforçava a referida leitura já realizada por Gilberto Freyre, e evidenciava um sentido justaposto a sua leitura histórica.

Mesmo um tema aparentemente distante da questão das subjetividades, a economia no futebol brasileiro, acabou sendo desenvolvido a partir do viés da brasilidade, vista como própria da configuração social brasileira. Trata-se da reconhecida análise de Ronaldo Helal acerca do processo de modernização e globalização do futebol brasileiro: o livro Passes e Impasses (1997) . O recorte se situa entre as décadas de 1970/1980. Helal propõe pensar sociologicamente e em termos de identidade a inserção do futebol e do brasileiro (que lembra muito o brasileiro de Gilberto Freyre) num mundo global sobre a economia de mercado. O pesquisador problematiza, dessa forma, os sentimentos desse brasileiro no futebol em um contexto de "nova ordem" no desporto nacional e mundial, afirmando que o brasileiro viveria um sentimento de dilema. Isto porque as modificações proporcionadas pela globalização do futebol teriam estimulado associações de grandes empresas ao esporte, resultando na adoção disseminada de imperativos de mercado para gestão do desporto. Neste cenário, o brasileiro se via ainda ligado afetivamente à necessidade de um "tradicionalismo e visão romântica" do jogo, porque este modelo seria aceito como o responsável pelo destaque do futebol brasileiro no cenário mundial no passado e, sendo assim o brasileiro reagiria de forma recalcada com a possibilidade de uma modernização

4 Mário Filho defende a ideia do brasileiro no futebol como um símbolo da representação do mestiço, tipo social construído por Gilberto Freyre como síntese do brasileiro comum, o qual seria caracterizado (entre outros atributos) pelo irracionalismo e a tendência à afetividade, ao contrário (por exemplo) do europeu que seria mais racional e mais formal.

5 Cf. HELAL, Ronaldo. Passes e Impasses: Futebol e cultura de massa no Brasil. Petrópolis, RJ: Vozes, 1997. 
para o futebol nacional. Dessa forma, códigos modernos passariam a chocar-se com códigos tradicionais no cerne da gestão do esporte no Brasil. Para Helal, essa nostalgia do brasileiro ajudaria a sustentar a permanência de um modelo arcaico de organização de futebol no país, que seria responsável por uma crise estrutural, descrita como sendo a de campeonatos desorganizados, jogos deficitários, êxodo de craques, espetáculos de baixa atratividade, amadorismo de dirigentes, fórmulas e calendário que careciam visão comercial.

A guisa de ilustração do protagonismo e permanência, ainda nos dias atuais, de abordagens em estudos de cunho históricos envolvendo a temática identidade nacional e futebol, apresento abaixo um levantamento que realizei sobre a produção historiográfica nos mais recentes encontros da ANPUH (Associação Nacional do Professores Universitários de História):

Tabela 1 - Produção acadêmica nos encontros da ANPUH nacional, e regional do Paraná, sobre a temática futebol e identidade nacional.
ANPUH NACIONAL - MONTEIRO, Vitor José da Rocha. "Em busca do método": Educação 2013 Física, corpo e identidade nacional entre civis e militares (1930- 1945).

ANPUH NACIONAL - SANTANA, Luiz Carlos Ribeiro. Adeus à viralatice: o filme Isto é Pelé 2013 (1974), o futebol e a ditadura.

ANPUH NACIONAL - GABRIEL, Bruno José. De qual futebol está falando? O contraste de 2013 um símbolo nacional na Folha de São Paulo.

ANPUH NACIONAL 2011

MARCZAL, Ernesto Sobocinski. Futebol, política e imprensa: representações sobre a vitória "brasileira" na Copa do Mundo de 1970.

ANPUH NACIONAL - $\quad$ LOPES, Gustavo Esteves. Brasileiras do Futebol: Contribuições para a 2011 História do Esporte (de sua origem moderna aos dias atuais).

ANPUH NACIONAL 2011

MARANHÃO, Tiago J. F. de Albuquerque. Apropriações do futebol como expressão da formação social brasileira.

ANPUH NACIONAL 2009

FREITAS JR, Miguel Arcanjo. Copa do Mundo de 1950: a criação de uma cultura da desculpa.

ANPUH NACIONAL 2009

ANPUH NACIONAL 2009

ANPUH PARANÁ 2016

ANPUH PARANÁ 2012
CHAGAS, Livia dos Santos. Brasil, pra sempre: futebol e política na revista Veja (1970).

SANTANA, Luis Carlos. Ginga: alma nacional, Expressão universal representações e aspirações de nacionalidade e pertencimento.

HAAG, Fernanda. "Chegou a hora dessa gente bronzeada mostrar seu valor": a publicidade televisiva e a brasilidade futebolística (1994-1998).

HAAG, Fernanda"\#vamosjogarbola": a publicidade e o futebol no Brasil (2000-2012)

Fonte: http://site.anpuh.org/, elaboração do autor (2017).

O levantamento foi buscado a partir dos títulos, ou palavras chave das comunicações, que utilizavam termos como "identidade e futebol", ou "identidade nacional e futebol", ou ainda "brasilidade e futebol". A pesquisa se fez a partir dos anais de encontros 
da ANPUH nacional e das regionais do Paraná e de São Paulo (para os encontros da regional de São Paulo não se obteve resultado relevante nos últimos oito anos, para a temática "futebol e identidade nacional"). Foram encontrados, também, alguns outros estudos que abordavam a identidade no futebol não necessariamente pela categoria da brasilidade (ou "identidade nacional") como, por exemplo, sobre "identidade regional e futebol", "identidade étnica" ou "identidade de gênero". Porém, o protagonismo da abordagem do esporte a partir da temática da identidade nacional se verificou mais recorrente. Isto não coloca em questão, obviamente, a qualidade desses trabalhos ou significa que todos eles incorporem a leitura freyreana de brasilidade. O que evidenciam é uma permanência disseminada e protagonista da abordagem do fenômeno esportivo por uma dada escolha (que consequentemente promove um sentido na leitura do passado e do presente), entre outras que seriam possíveis, no campo acadêmico de estudos históricos do desporto no Brasil.

\section{Subjetividades no futebol brasileiro: leituras que problematizam a categoria da brasilidade}

Há, conforme citado, certo número de obras nas ciências humanas que não necessariamente seguem a perspectiva freyreana, na análise das subjetividades e identidades no futebol brasileiro. Algumas, entretanto, abordam a questão de forma mais pronunciada, e nesse sentido escolhemos algumas leituras que consideramos referenciais.

Sendo assim, um exemplo de interpretação que não segue a linha freyreana, remete a Toledo (2002) no livro denominado Lógicas no futebo/ ${ }^{6}$ em que propõem uma análise nacional do futebol (discutindo também identidades), mas também não parte de um suposto "ethos" brasileiro. O recorte trata do decorrer do século XX. A abordagem é antropológica e o pesquisador inova buscando problematizar o futebol e identidades no país, a partir do que chama "mediadores especializados": os profissionais, os torcedores e os cronistas, entre os quais teria se desenvolvido "um complexo sistema de relações, trocas e prestações" em torno das partidas de futebol, ou sobre o cotidiano. Sobre o domínio profissional, por exemplo, Toledo demonstra o destaque e a consagração, nesse plano, de manuais, saberes e referências que se almejam "técnicos" para o futebol. Expressões não reduzidas, dessa forma portanto, a uma evocação de matriz racialista ou "nacional" sobre como "jogar bem". Sobre as identidades, Toledo destaca que o simbolismo transita entre esses "mediadores especializados", defendendo-se e sustentando-se (agora sim) determinadas formas de jogar (ex. jogar "à gaúcha" ou "jogar à brasileira"), de comentar ou de torcer, mais do que outras. Essas expressões de identidade seriam, dessa forma, um processo que reuniria atores diferentes num processo dinâmico, mutável e sempre reflexo de disputas.

Em 1998, há um trabalho que provavelmente inaugura uma problematização sobre a narrativa histórica tradicional (acadêmica ou não) envolvendo futebol e identidade nacional de forma acentuada. Trata-se da tese de doutoramento de Antônio Jorge Soares, denominada Futebol, raça e nacionalidade no Brasil: releitura da história oficial. O recorte

6 Cf. TOLEDO, Luiz Henrique de. Lógicas do futebol. São Paulo: Hucitec/Fapesp, 2002. 
é o decorrer século XX. É difícil o acesso à tese, entretanto Soares reporta-se a ela em alguns artigos que escreve posteriormente. Para o autor, Mário Filho teria inspirado um pressuposto acrítico para seus sucessores (seja no domínio acadêmico ou fora dele) de se entender o futebol como apropriado pelas classes populares no Brasil. Esta apropriação teria a forma de resistência cultural do negro e do mestiço, processo que teria servido também para sua aceitação e emancipação social, bem como para a criação de um estilo próprio do futebol brasileiro, inaugurando a democracia racial no país e a própria identidade nacional. Soares critica esse modelo como sendo, na verdade, uma "invenção de tradição" sobre o futebol e a identidade nacional no Brasil, já que careceria de provas exigidas pelo rigor crítico da academia. Cabe ressaltar que o argumento de Soares fomentou grande debate neste campo de estudos e há divergências sobre as suas conclusões ${ }^{7}$.

Finalmente, acrescentamos a análise oferecida pelo historiador Luiz Carlos Ribeiro, o qual problematiza o campo de estudos das ciências humanas para os esportes no país. Este teria se desenvolvido, ainda, como herdeira de uma História que tinha para si a missão de atingir uma modernidade para o Brasil, cujos historiadores Gilberto Freyre e Sérgio Buarque de Hollanda figuraram como expoentes, em dado momento. Na perspectiva apontada por Ribeiro, propõe-se um estudo do fenômeno esportivo buscando pensá-lo a partir não apenas da objetividade e da razão, mas também da subjetividade das emoções e dos sentimentos. Nessa linha, ainda, os sentimentos, as paixões, deveriam ser estudados e entendidos enquanto protagonistas historicamente, e não como desvios sem importância nos acontecimentos como faria uma determinada tradição nas ciências sociais. Assim, se deveria evitar a história calcada apenas sobre aspectos "sérios" e "racionais" da vida, como se fossem os "reais" e "legítimos" motores da história, em detrimento dos aspectos "lúdicos" e também "irracionais" do ser humano. Nessa mesma perspectiva, não se deveria colar a paixão futebolística a uma identidade brasileira pré-definida, como ainda fariam alguns estudos. Afinal, essa experiência aconteceria historicamente, não seria dada à priori. Ainda, ela seria anterior, multifacetada e mesmo desligada a uma consciência de identidade. Não se deveria reduzir a polissemia a uma essência, mas sim problematizar a paixão futebolística enquanto uma experiência de vida, individual, social, local (RIBEIRO, 2012).

\section{CONCLUSÕES}

Conforme exposto, a identidade é um tema recorrente nos estudos sobre futebol no Brasil. Neste campo acadêmico predomina uma leitura que se caracteriza pelo uso da categoria brasilidade, para entender os fenômenos sociais no esporte. Esta categoria acaba revelando um dado sentido na percepção da realidade social, e um determinado projeto sobre como interferir nela. Essa constatação é salutar, levando-se em conta as discussões em torno dos limites de cientificidade das ciências humanas e da história.

7 Cf. MURAD, Mauricio. Considerações possíveis de uma resposta necessária. Estudos Históricos. Rio de Janeiro, v.13, n.24, p.431-446, 1999. 
Se situarmos essa constatação na discussão sobre crise, antes apresentada nos dias atuais na historiografia, poderíamos citar a existência de pelo menos dois "processos de geração de sentido" que expusemos, e que a própria configuração esportiva oferece ao historiador: brasilidade e regionalidade. A bibliografia, na maioria dos casos, porém, acaba apropriando-se mais frequentemente de uma delas, revelando um sentido mais proeminente de leitura do passado: narrativas de brasilidade, que evocam indiretamente uma modernidade para o Brasil.

A simples valorização de narrativas regionalistas nos levaria, também, ao mesmo problema, embora o ponto de partida fosse inverso: almejar uma história dos paranaenses, paulistas, mineiros no futebol sem a devida problematização do próprio uso da categoria pelos atores sociais no tempo, imiscuiria essas análises como mais um meio para evocar uma modernidade para estas unidades federativas, e elas permaneceriam vulneráveis a crítica de representarem apenas romances. O que essas categorias regionalistas evidenciam são justamente as contradições de uma ideia pretensa de totalidade a partir da categoria de brasilidade, embora a categoria de brasilidade possa muito bem ser entendida como uma forma de habitus social disseminado, que conforma determinados grupos, mas não entendida e utilizada como essência, totalizante e sem historicidade. A questão que se coloca, enfim, é perceber essas manifestações de brasilidade, regionalidade, e outras construções identitárias, como apropriações de subjetividades que se constroem socialmente e historicamente, e não categorias que expressariam características inatas aos indivíduos.

Assim, conforme explicitado anteriormente, pode-se afirmar que o grande desafio dos historiadores, atualmente, é superar a crise que envolve a História enquanto ciência. Critica-se a modernidade, frequentemente, pelo fato desta não ter cumprido a missão que ela mesma atribuiu-se historicamente. Ou seja, o de um projeto mundial de "liberdade, igualdade e fraternidade". Critica-se a História, enquanto ciência, por esta consagrar um sentido de racionalidade dos indivíduos, ou de trabalhar com categorias apriorísticas e desconectadas da experiência, e que evocam de forma dissimulada uma modernidade enquanto um processo histórico, soterrando as subjetividades presentes na própria História. Finalmente, problematiza-se o status da História enquanto ciência e enquanto verdade, porque ela se realizaria por meio da linguagem (narrativa, historiografia), expressão cultural e subjetiva por excelência, além de abordagens que consagrariam determinados sentidos de percepção da realidade em detrimento de outras. Essas questões ficam evidenciadas pelo exemplo do estudo das identidades no futebol.

Jorn Rüsen nos oferece uma proposta que restituiria a História enquanto ciência: reconhecer as diferenças enquanto uma característica que define a nossa universalidade, e que há circunstâncias objetivas para a possibilidade da própria história da humanidade, que superam as subjetividades:

Apesar disso devemos reconhecer que há uma tensão, uma descontinuidade ou um abismo entre a autoconsciência e a auto-interpretação do homem e das circunstâncias previamente dadas em sua vida; essa ruptura deveria ser examinada e interpretada pelos historiadores (RUSEN, 2013:12). 
Um intelectual, já com certa utilização acadêmica nos estudos do esporte, seria uma boa possibilidade visualizada, para encaixe à proposta oferecida por Rüsen: Norbert Elias.

Elias não é um autor proveniente da História, e sim da sociologia. Possui uma vasta bibliografia abordando diversas temáticas. É um autor reconhecido nas ciências humanas, sendo uma referência importante em vários estudos da História e também em estudos sobre os esportes, tema que ele concedeu especial atenção em sua obra $A$ busca da excitação ${ }^{8}$. Seu principal trabalho, O processo civilizador, trata justamente de uma transformação histórica que acontece na sociedade europeia, e ele analisa essa transformação debruçando-se tanto sobre os indivíduos quanto sobre a sociedade, entes que ele conjuga como inter-relacionados num mesmo processo social e histórico.

Isto acontece porque o sociólogo desenvolve sua metodologia de análise através da chamada teoria configuracional. A partir dela, considera os processos sociais não desligados dos processos subjetivos: ou seja, não seriam desligados das emoções e sentimentos dos indivíduos. Neste caso, Elias revela suas influências da psicanálise, e (portanto) desse modo seu método superaria as críticas direcionadas a historiografia tradicional, já que "revisitaria" o passado dando luz às unidades, às subjetividades, às pluralidades, enfim às emoções.

Por outro lado, a teoria de Elias serve para traçar também um olhar estrutural sobre os processos sociais, o que permite visualizar não apenas uma leitura sociológica dos processos históricos, mas perceber uma unidade nesse fenômeno configurado por tantas diferenças e disputas. Este traço da teoria de Norbert Elias revela as suas influências de Max Weber, Karl Marx e Emile Durkheim.

O encaixe entre unidade e subjetividades, na teoria elisiana, poderia ser visto a partir do funcionamento de dois mecanismos sociais apontados pelo sociólogo: psicogênese e sociogênese, Psicogênese seria como o sujeito se adaptaria no tecido social controlando suas emoções, suas pulsões, a fim de atingir seus objetivos individuais. Uma forma, portanto, de civilidade apreendida como estratégia para conduzir a si (mecanismo orientador) a um bem-estar efetivamente real e duradouro da sua individualidade. Na medida em que esse processo aconteceria disseminado entre vários indivíduos, poderia ser visto como um processo social, ou seja, um processo de sociogênese e de sentido civilizatório à sociedade, em última análise.

Uma leitura dinâmica desse encaixe poderia ser exemplificada pelo destaque do intelectual às redes sociais, as quais refletiriam alianças e disputas entre indivíduos e grupos. O estudo de como se constroem e o que significariam essas alianças e disputas, inclusive em termos de sentimentos e de expressões de identidades, e o porquê de algumas narrativas de identidade se consagram mais que outras para definir a totalidade dos indivíduos, podem ser pontos de referência para explorar a teoria elisiana na história do esporte.

Assim, em síntese, a perspectiva de Norbert Elias possibilita não uma afirmação inicial, e totalizadora (por exemplo) sobre as identidades, mas sim enxergá-las tal como 
elas se constroem historicamente, ou seja, como querem ser vistas, sem compromissos estabelecidos de antemão. Isto para que o passado seja contado, ou restituído, dando luz às subjetividades, emoções e as pluralidades, é dizer: dos vários sentidos que a realidade social é apreendida por diferentes indivíduos e grupos em disputa. Essa possibilidade ficaria soterrada quando se faz uma leitura da realidade a partir de categorias pré-estabelecidas e que limitam a visão do passado (e do presente) a certo sentido como, por exemplo, a partir da categoria "identidade nacional" no futebol.

Ao mesmo tempo, a perspectiva do sociólogo também estabelece um sentido de unidade nessas configurações que conformam pluralidades. Essa unidade é a sociedade, ou o que ele chama de a sociedade dos indivíduos. Na medida em que se tem um norte de unidade social, esta abordagem permite também uma unidade de verdade e de sentido: portanto vislumbra-se uma universalidade, e (portanto) também a existência da História como ciência.

O exemplo oferecido, da teoria elisiana, obviamente não é o único possível. Mas é uma possibilidade e serve como exemplo ilustrativo para a escrita da história do esporte com pretensões de cientificidade, na perspectiva de Rüsen. É, enfim, um caminho que parece oportuno para o desenvolvimento de estudos sobre esportes nas ciências humanas. Assim, a análise dos fenômenos históricos esportivos não ocorreria com categorias pré-estabelecidas, mas através da problematização das expressões que emergem, como o regionalismo e brasilidade, ou outras que se apresentem. O desafio seria entendê-las como inter-relacionadas num processo que envolve uma configuração global e plural de disputas, num presente em que o Estado-nação e a ideologia que o sustentava, apresentam cada vez mais sinais de corrosão e declínio. Em última análise, isso significa a manutenção de um compromisso: pensar a história como ciência, e pensá-la como fenômeno de uma sociedade sustentável e efetivamente plural, ainda que não mais confinada aos limites e ideais das antigas nações:

Será possível integrar em uma síntese a razão e a imaginação, a racionalidade e a narrativa, a orientação prática e o fascínio estético? Logicamente isso é possível. Para implementar essa integração na prática, precisamos analisar criticamente o significado instrumental da palavra "razão" e sua influência na dominação por meio da compreensão e do conhecimento. Criticar esse significado instrumental da razão não nos deve levar necessariamente a um novo irracionalismo, risco presente em muitos enfoques pós-modernos da história. Deveríamos reformular os critérios da razão, do método, da argumentação e - peço vênia para usar essa palavra - da racionalidade com referência à estrutura narrativa e ao processo da evocação histórica, assim como deveríamos reformular a influência da evocação histórica sobre a imaginação. Talvez isso traga algum progresso para a concepção da razão na história (RÜSEN apud RÜSEN 2013: 13) 


\section{REFERÊNCIAS}

CHARTIER, Roger. À beira da falésia: a história entre incertezas e inquietude. Porto Alegre: Editora UFRGS, 2002.

DAMATTA, Roberto. Antropologia do óbvio - Notas em torno do significado social do futebol brasileiro. Revista Usp, [s.I.], n. 22, p.10-17, 30 ago. 1994.

DAMO, Arno S. Do Dom à Profissão. Tese (Doutorado em Antropologia). Porto Alegre: Universidade Federal do Rio Grande do Sul, 2005.

- Para o que der e vier: o pertencimento clubístico no futebol brasileiro a partir do Grêmio Foot-Ball Porto Alegrense e seus torcedores. Dissertação (Mestrado em Antropologia Social). Porto Alegre: Instituto de Filosofia e Ciências Humanas, Universidade Federal do Rio Grande do Sul, 1998.

ELIAS, Norbert. A Sociedade dos Indivíduos. Rio de Janeiro: Jorge Zahar Editores, 1994.

FREYRE, Gilberto. Sociologia. Rio de Janeiro: José Olympio, 1967.

GINZBURG, Carlo. Relações de força. São Paulo: Companhia das Letras, 2002.

HELAL, Ronaldo. Mídia, construção da derrota e o mito do herói. In: SOARES, Antonio Jorge; LOVISOLO, Hugo; HELAL, Ronaldo G. A invenção do país do futebol: mídia, raça e idolatria. Rio de Janeiro: Mauad, 2001.

MEMÓRIA do futebol paranaense: entrevista com Capitão Hidalgo. Curitiba: Núcleo de Estudos Futebol e Sociedade, 2011. Son., color. Disponível em: < https://www.youtube. com/watch?v= P9VBZdDMczA > . Acesso em: 12 ago. 2017.

RÜSEN, Jörn: "O que é meta história", Capítulo 1. Curitiba: Labhistória/ufpr, 2011. Son., color. Disponível em: < https://www.youtube.com/watch?v=3pqSQ97lgEE > . Acesso em: 1 ago. 2015.

. A história entre a modernidade e a pós-modernidade. Palestra realizada na Universidade Federal do Paraná, 2013.

. História viva. Brasília : UnB, 2007.

. Razão histórica, teoria da história: os fundamentos da ciência histórica. Brasília: UnB, 2001.

WHITE, Hayden. Trópicos do discurso: ensaios sobrea crítica da cultura. Tradução Alípio Correia de Franca Neto. 2a ed. São Paulo: EDUSP, 2001.

Recebido em: Outubro/2017 Aprovado em: Fevereiro/2018 